\title{
Study on Physicochemical Properties of Milk Beverage
}

\author{
S. Niveadhitha ${ }^{1^{*}}$ and D. Ramasamy ${ }^{2}$ \\ ${ }^{1}$ College of Food and Dairy Technology, Chennai, Tamil Nadu, India \\ ${ }^{2}$ Department of Food Processing Technology, College of Food and Dairy Technology, \\ Chennai, Tamil Nadu, India \\ *Corresponding author
}

A B S T R A C T

\section{Key w o r ds \\ Milk beverage, Beetroot, Banana \\ Article Info \\ Accepted: \\ 18 April 2018 \\ Available Online: \\ 10 May 2018}

In today's world, beverages are no longer considered as thirst-quenchers; consumers look for specific functionality and it becomes a part of their lifestyle. In recent years, these changes and developments have led to newer products. Red beetroot (Beta vulgaris L.) is a rich source of dietary nitrate which significantly reduces systolic blood pressure in humans. Banana (Musa spp.) is a major source of potassium and total dietary fibres. Hence our project was aimed to develop milk beverage with fortification of beet and banana. In our studies, various combination of milk, beetroot and banana were tried. Milk beverage was standardized based on sensory scores using 9-point Hedonic scale. Standardized milk beverage was studied for its physicochemical properties such as moisture, total sugars, titratable acidity, $\mathrm{pH}$, total solids, total soluble solids, viscosity and colour were studied.

\section{Introduction}

The functional beverages can play a vital role in wellbeing and disease prevention. These reduce increasing encumber on health care system by an uninterrupted preventive mechanism (Shahidi, 2004). Beverages are considered to be an exceptional medium for the supplementation of nutraceutical components for fortification (Kuhn, 1998) such as soluble fibre or herbal extract (Swientek, 1998). The functional beverages provide necessary nutrients to prevent nutrition-related diseases beyond taste and refreshment satisfaction (Menrad et al., 2000). There is enormous number of food products taken as beverages such as coffees, iced teas, herbal teas, sports drinks, frozen carbonated beverages, fruit and vegetable juices and smoothies (Giese, 1992).

Red beetroot (Beta vulgaris L.) is a member of the Chenopodiaceae family grown all over the world and edible part is the root which is consumed in various forms, i.e., as fresh vegetable, juice, desiccated and frozen product and as a natural pigment.

Beetroot is a rich source of dietary nitrate and several reports indicated its potential for significantly reducing systolic blood pressure in humans. Consumption of beetroot juice and bread products enriched with red or white beetroot lowered systolic BP and diastolic BP (Hobbs et al., 2012). Banana (Musa spp.) is a well-known tropical fruit. It is a major source 
of macro elements, especially potassium and contains health good ingredients such as resistant starch, total dietary fibers, rapidly digestible starch and slowly digestible starch. Its role to regulate blood pressure has been associated with the high content of potassium. Owing to its high iron content, banana is mainly recommended for anaemic patients and was also proven to be beneficial in controlling blood pressure as it has low salt and high potassium content (Singh et al., 2016).

In this study, milk beverage was produced using banana and beetroot. In addition to the nutritive value, banana and beetroot will act as flavouring agent and colouring agent. The addition of banana will make beetroot more appetizing. The physicochemical properties of milk beverage were studied.

\section{Materials and Methods}

\section{Materials}

Fresh toned milk of $3 \%$ fat and $8.5 \% \mathrm{SNF}$ obtained from the Aavin was used for this study. Musa spp. (Grande Naine) used in the study were procured from local market at the maturity index of 7. Fresh red, well matured and uniform sized beetroots with no blemishes were obtained from the local market for experimentation.

\section{Preparation of milk beverage}

Fully ripened banana were peeled and blended in a house hold mixer grinder. Fresh beetroots were washed thoroughly, cut into small pieces and pressure cooked for 20 minutes.

After cooling, it was pureed using house hold mixer grinder. Toned milk was pre-heated to $60^{\circ} \mathrm{C}$ and used for further processing. Milk beverage was processed as per the flow chart mentioned in figure 1. Different ratio of banana pulp and beetroot pulp were mixed with pre-heated toned milk for preparation of milk beverage, as shown in Table 1 .

\section{Sensory evaluation}

Sensory evaluation of prepared milk beverage using 9- point Hedonic scale (Larmond, 1977) was carried out by panel of judges comprising of six members. All the samples were appropriately coded before subjected to sensory evaluation.

\section{Physiochemical properties of milk beverage}

\section{Moisture content}

The moisture content of the milk beverage was determined by the AOAC (2007) method. The weight loss percentage (\%) after ovendrying at $105{ }^{\circ} \mathrm{C}$ until a constant weight was obtained and moisture content (\%) was calculated.

\section{Total sugars}

Total sugars were determined by method of Lane and Eynon (1923) as reported by Ranganna (1986)

\section{Titratable acidity}

Titratable acidity (TA) of milk beverage samples was determined by visual titration method (Ranganna, 1986).

\section{pH}

A $\mathrm{pH}$ meter is an electronic instrument used for measuring the $\mathrm{pH}$ (acidity or alkalinity) of a liquid (through special probes are sometimes used to measure the $\mathrm{pH}$ of semi-solid substances). A typical $\mathrm{pH}$ meter consists of a special measuring probe (a glass electrode) connected to an electronic meter that measures and displays the $\mathrm{pH}$ reading. The $\mathrm{pH}$ meter was calibrated with commercial buffer 
solutions at $\mathrm{pH} 9.1$ and 4.0 before measurement. About $10 \mathrm{ml}$ sample was inserted with a $\mathrm{pH}$ electrode and $\mathrm{pH}$ was recorded after stabilization.

\section{Total solids}

The total solid content (\%) of the milk beverage was calculated by using the formula:

Total Solids $(\%)=100$-Moisture Content

\section{Total soluble solids}

The total soluble solids (TSS) content was determined at ambient temperature $\left(28 \pm 2^{\circ} \mathrm{C}\right)$ by digital Refractometer (RX-7000 $\alpha$, Atago India Instruments Pvt. Ltd., India). The refractometer was calibrated with distilled water before measuring TSS of the sample. TSS was measured by placing a drop of milk beverage on the prism of the refractrometer. An average of 6 readings was recorded as TSS and expressed as ${ }^{\circ}$ Brix.

\section{Viscosity}

Viscosity of the milk beverage was measured with a Rotational Viscometer (Cole-Parmer, India) using Spindle \#3.

\section{Colour}

Colour in the food is due to presence of natural pigment like anthocyanins, carotenoids or chlorophyll. Colour measurement was carried out using a Hunter Colorimeter model 45/0-L mini scan XE PLUS (Hunter Associates Labs, Reston, VA, USA) on the basis of three variables, namely, L, a, and b.

The colour of the milk beverage was measured by a Hunter Colorimeter. First the colorimeter was calibrated using the standard black and white tile $\left(\mathrm{L}^{*}=93.51, \mathrm{a}^{*}=-0.72\right.$ and $\mathrm{b}^{*}=$ 0.31). Samples were kept against instrument (sample) port, making sure that it is completely covered by the area to be measured. The measurements were performed in two replications and repeated three times per replicate. The results were expressed as an average value of all the samples. Hue and chroma values were obtained from $a^{*}, b^{*}$ value using the following formula,

Hue $=\tan ^{-1}\left(b^{*} / a^{*}\right)$

Chroma $=\sqrt{a^{2}}+b^{2}$

\section{Statistical analysis}

The data obtained in all the experiments were analyzed statistically by applying one way ANOVA in IBM SPSS® software (version 20.0) for windows as per the standard procedure of Snedecor and Cochran, 1994.

\section{Results and Discussion}

\section{Standardization of milk beverage based on sensory}

Statistical analysis showed that a highly significant $(\mathrm{P}<0.01)$ difference was observed in all treatment with regard to colour and appearance, flavor, body and texture and overall acceptability. The highest mean value for overall acceptability was recorded in treatment $\mathrm{T}_{19}$ when compared to other treatments. Hence the milk beverage prepared in the ratio 4:4:4 of milk, banana and beetroot respectively was selected and standardized for further studies. Sensory scores of different treatments of milk beverage have been represented pictorially using radar diagram (Fig. 1-5).

\section{Physiochemical properties of milk beverage}

Milk beverage contained moisture 87.88 per cent, total sugar $7.25 \%$, titratable acidity 0.96 $\%$ lactic acid, $\mathrm{pH} 5.54$, total solids $12.12 \%$, TSS $8.00 \%$ and viscosity $1077 \mathrm{cp}$. 
Table.1 Ratio of milk, banana pulp and beetroot pulp

\begin{tabular}{|c|c|}
\hline Treatments $(\mathrm{T})$ & Milk : Banana Pulp : Beetroot pulp \\
\hline $\mathrm{T}_{1}$ & $4: 1: 1$ \\
\hline $\mathrm{T}_{2}$ & $4: 2: 1$ \\
\hline $\mathrm{T}_{3}$ & $4: 3: 1$ \\
\hline $\mathrm{T}_{4}$ & $4: 4: 1$ \\
\hline $\mathrm{T}_{5}$ & $4: 5: 1$ \\
\hline $\mathrm{T}_{6}$ & $4: 1: 2$ \\
\hline $\mathrm{T}_{7}$ & $4: 2: 2$ \\
\hline $\mathrm{T}_{8}$ & $4: 3: 2$ \\
\hline $\mathrm{T}_{9}$ & $4: 4: 2$ \\
\hline $\mathrm{T}_{10}$ & $4: 5: 2$ \\
\hline $\mathrm{T}_{11}$ & $4: 1: 3$ \\
\hline $\mathrm{T}_{12}$ & $4: 2: 3$ \\
\hline $\mathrm{T}_{13}$ & $4: 3: 3$ \\
\hline $\mathrm{T}_{14}$ & $4: 4: 3$ \\
\hline $\mathrm{T}_{15}$ & $4: 5: 3$ \\
\hline $\mathrm{T}_{16}$ & $4: 1: 4$ \\
\hline $\mathrm{T}_{17}$ & $4: 2: 4$ \\
\hline $\mathrm{T}_{18}$ & $4: 3: 4$ \\
\hline $\mathrm{T}_{19}$ & $4: 4: 4$ \\
\hline $\mathrm{T}_{20}$ & $4: 5: 4$ \\
\hline $\mathrm{T}_{21}$ & $4: 1: 5$ \\
\hline $\mathrm{T}_{22}$ & $4: 2: 5$ \\
\hline $\mathrm{T}_{23}$ & $4: 3: 5$ \\
\hline $\mathrm{T}_{24}$ & $4: 4: 5$ \\
\hline $\mathrm{T}_{25}$ & $4: 5: 5$ \\
\hline
\end{tabular}

The ratio of the milk beverage was standardised based on sensory evaluation.

Table.2 Physicochemical properties of processed milk beverage

\begin{tabular}{|l|}
\hline Physicochemical properties \\
\hline Moisture content (\%) \\
\hline Total Sugar (\%) \\
\hline Titratable Acidity (\% lactic acid) \\
\hline pH \\
\hline Total solids (\%) \\
\hline TSS (\%) \\
\hline Viscosity (cp) \\
\hline
\end{tabular}

\begin{tabular}{|l|}
\hline Milk Beverage \\
\hline $87.88 \pm 3.04$ \\
\hline $7.25 \pm 0.09$ \\
\hline $0.96 \pm 0.03$ \\
\hline $5.54 \pm 0.04$ \\
\hline $12.12 \pm 0.07$ \\
\hline $8.00 \pm 0.80$ \\
\hline $1077 \pm 1.41$ \\
\hline
\end{tabular}


Table.3 Colour values of milk beverage

\begin{tabular}{|l|l|l|} 
Colour & L & $39.82 \pm 0.01$ \\
\hline a & $37.66 \pm 0.03$ \\
\hline b & $3.90 \pm 0.04$ \\
\hline Hue & $5.912 \pm 0.06$ \\
\hline Chroma & $37.86 \pm 0.06$
\end{tabular}

Fig.1 Sensory scores of treatments $\left(T_{1}-T_{5}\right)$ of milk beverage

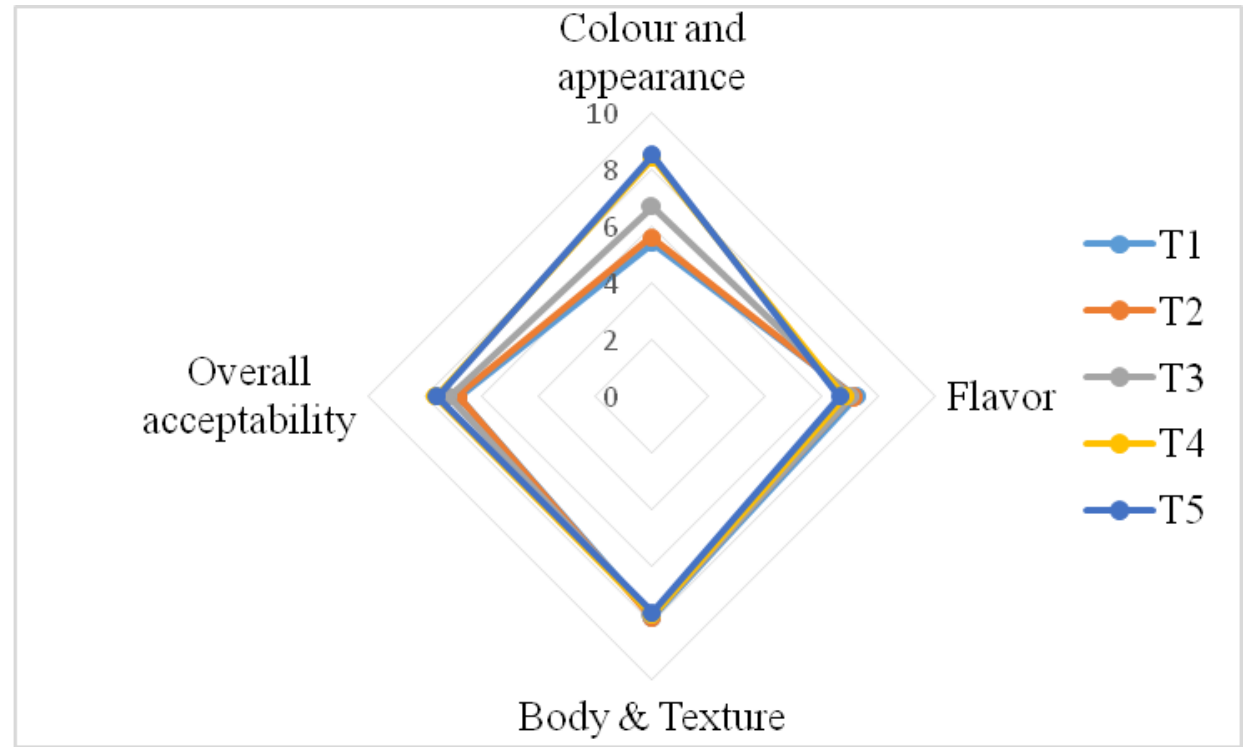

Fig.2 Sensory scores of treatments $\left(\mathrm{T}_{6}-\mathrm{T}_{10}\right)$ of milk beverage

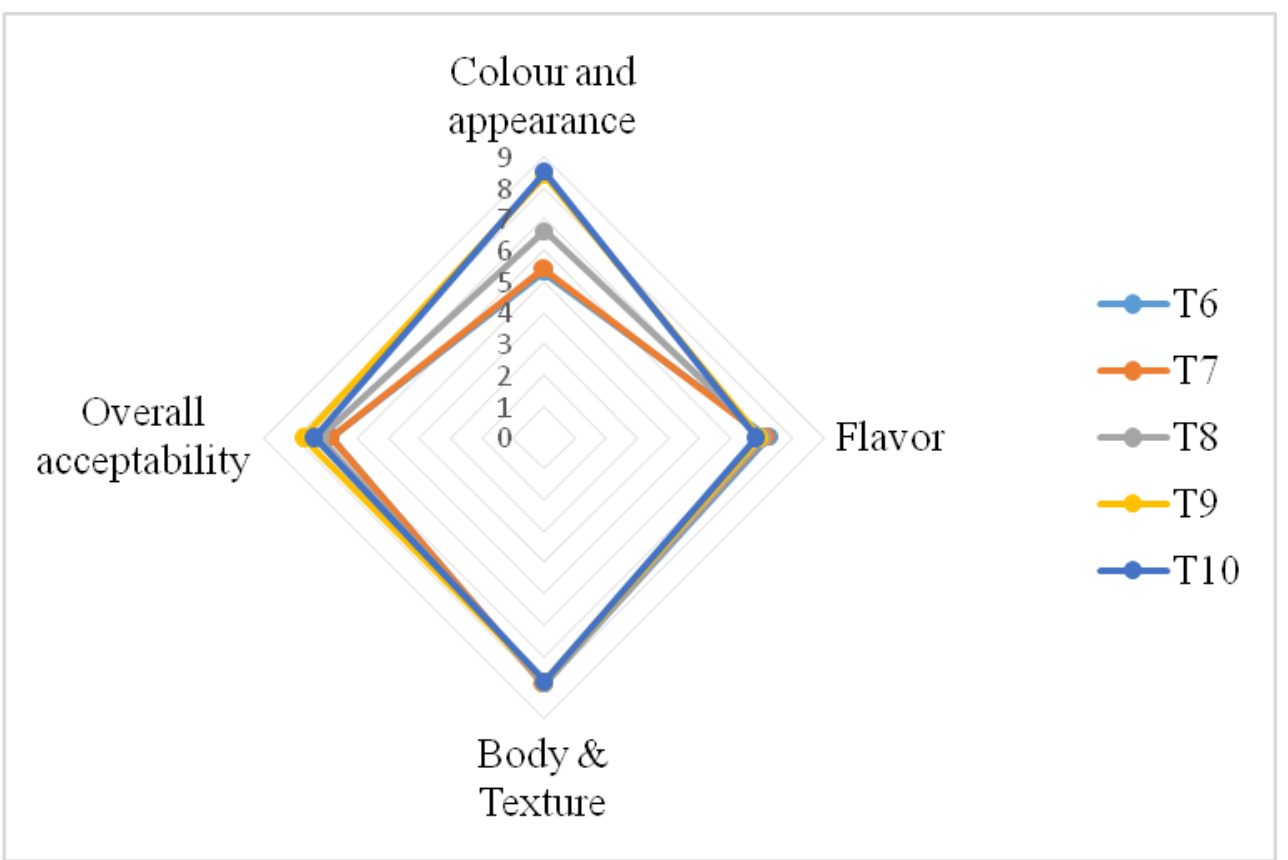


Fig.3 Sensory scores of treatments $\left(\mathrm{T}_{11}-\mathrm{T}_{15}\right)$ of milk beverage

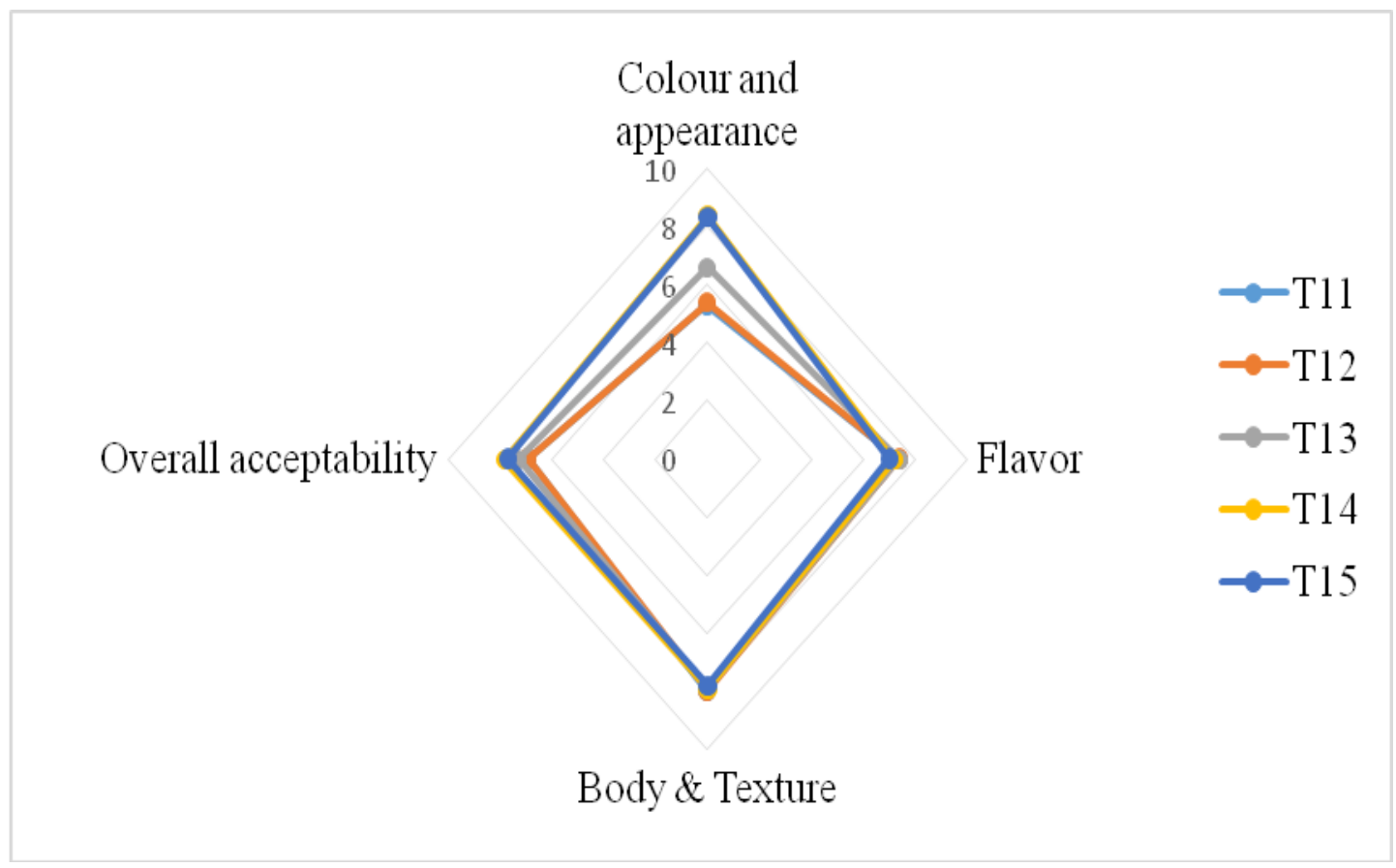

Fig.4 Sensory scores of treatments $\left(\mathrm{T}_{16}-\mathrm{T}_{20}\right)$ of milk beverage

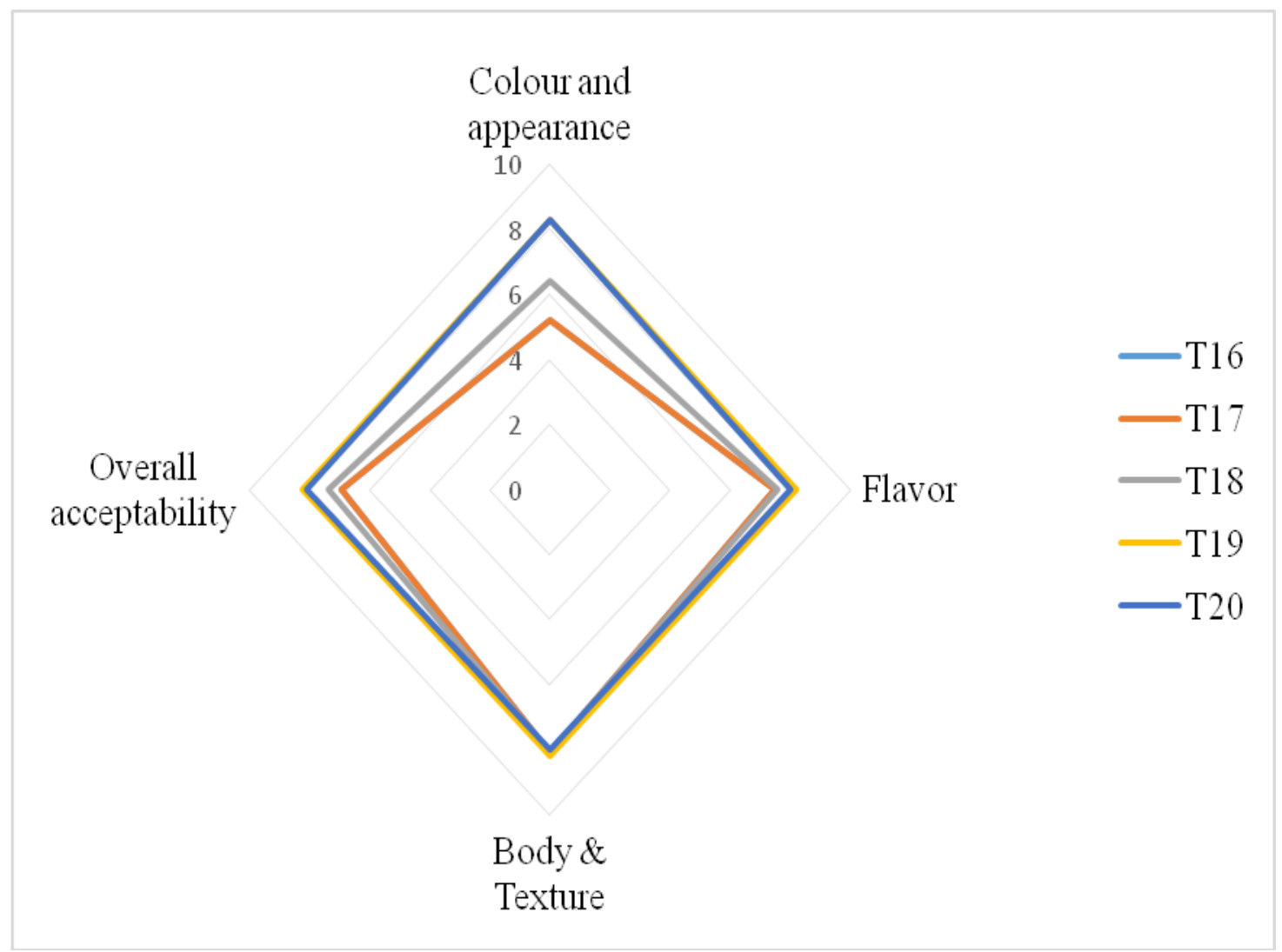


Fig.5 Sensory scores of treatments $\left(\mathrm{T}_{21}-\mathrm{T}_{25}\right)$ of milk beverage
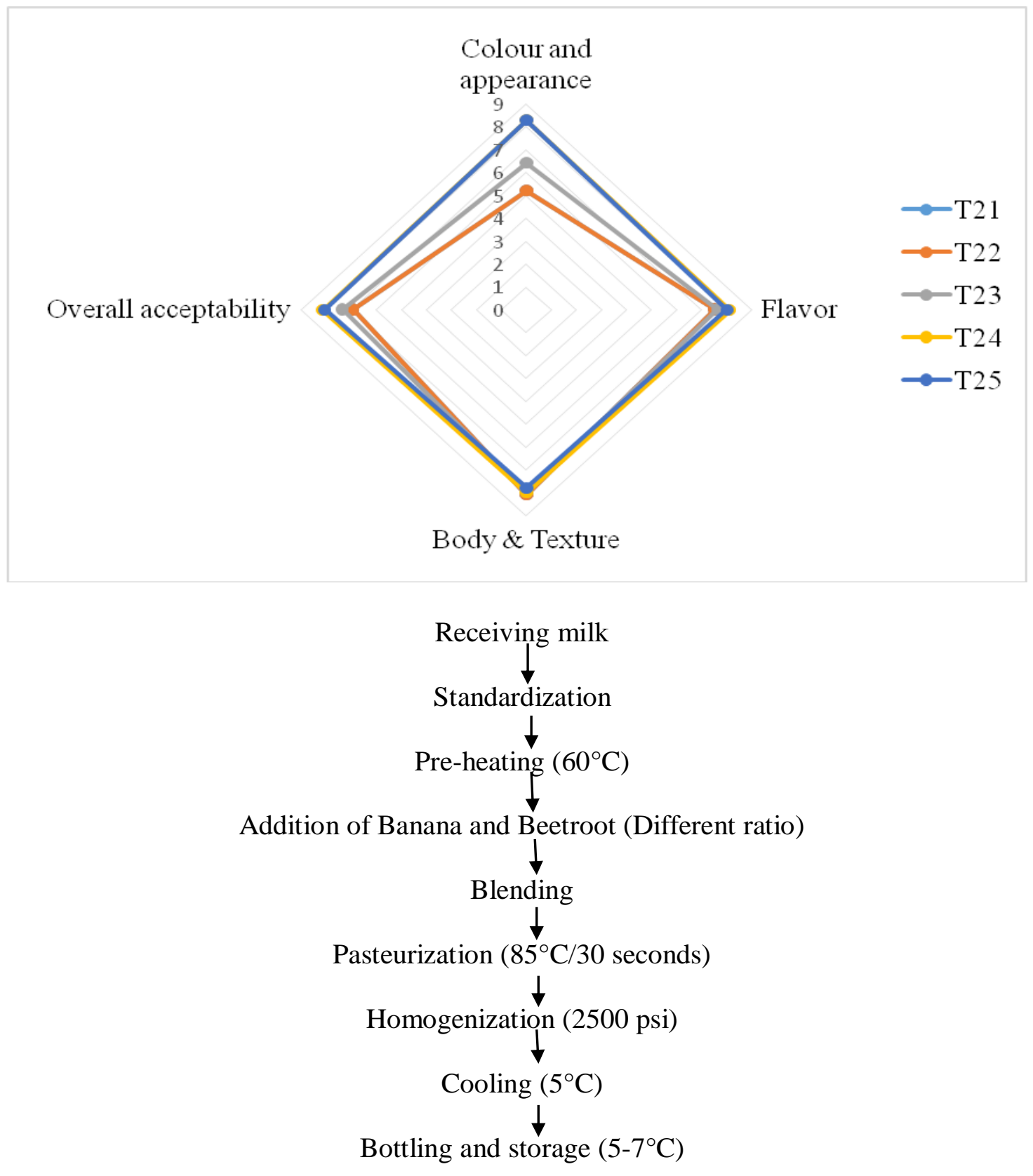

Fig. 2.1 Flow chart for preparation of milk beverage

The physicochemical properties of most preferred processed milk beverage are given in Table 2. The values in the table are indicative of a milk beverage found most acceptable by sensory evaluation. Similar study has been carried out for mango milk beverage (Ahlawat, 2007).

\section{Colour values of milk beverage}

Colour value L 39.82, a* 37.66, b* 3.90, Hue 5.912 and Chroma 37.86 given in Table 3 indicate that product is towards redness due to presence of red beetroot in the milk beverage which is a rich source of red and yellow 
pigments known as betalains. Milk beverage prepared with banana and beetroot had a pleasant colour and flavour with acceptable taste. Milk beverage in the ratio of $4: 4: 4$ have scored the highest among the different treatments. Banana and beetroot helps in reducing the blood pressure due to presence of potassium and dietary nitrate respectively. This milk beverage can be consumed as such or its shelf life can be increased by spray drying which gives ready to eat product with good quality parameters. This milk beverages can been claimed to be ideal due to its inherent nutrient content as well as sensory appeal and health promoting attributes.

\section{References}

Ahlawat, D. (2007). Studies on production and packaging of mango milk powder using spray drying technology.

Association of Official Analytical Chemists AOAC. Official methods of analysis. 17th ed. Maryland: AOAC, 2007.

Giese, J.H. 1992. Hitting the spot: Beverages and beverage technology. Food Technol. 46:70-80.

Hobbs, D. A., Kaffa, N., George, T. W., Methven, L., and Lovegrove, J. A. (2012). Blood pressure-lowering effects of beetroot juice and novel beetrootenriched bread products in normotensive male subjects. British Journal of Nutrition, 108(11), 20662074.

Kuhn, M. E. 1998. Functional food overdose. Food Proc. Mag. 59(5):21-48.

Larmond, E. (1977). Laboratory Methods for Sensory Evaluation of Foods. Canada Department of Agriculture, Pub., 1637.

Menrad, M., B. Husing, K. Menrad, T. Reib, S. Beer-Borst and C.A. Zenger. 2000. Functional Food. TA 37/2000. Bern: Schweizerischer Wissenschafts undTechnologierat.

Ranganna, S., 1986. Manual of Analysis of Fruit and Vegetable Products. Tata McGraw Hill Publishing Company Ltd. New Delhi. Pp. 7-12 and 109.

Shahidi, F. 2004. Functional foods: Their role in health promotion and disease prevention. J. Food Sci. 69(5):146-149.

Singh, B., Singh, J.P., Kaur, A., Singh, N., Bioactive compounds in banana and their associated health benefits - a review, Food Chemistry (2016), doi: http://dx.doi.org/10.1016/j.foodchem. 2016.03.033

Swientek, B. 1998. Toasts of the town. Prep. Foods. Pp. 21-26.

\section{How to cite this article:}

Niveadhitha, S. and Ramasamy, D. 2018. Study on Physicochemical Properties of Milk Beverage. Int.J.Curr.Microbiol.App.Sci. 7(05): 2421-2428.

doi: https://doi.org/10.20546/ijcmas.2018.705.278 